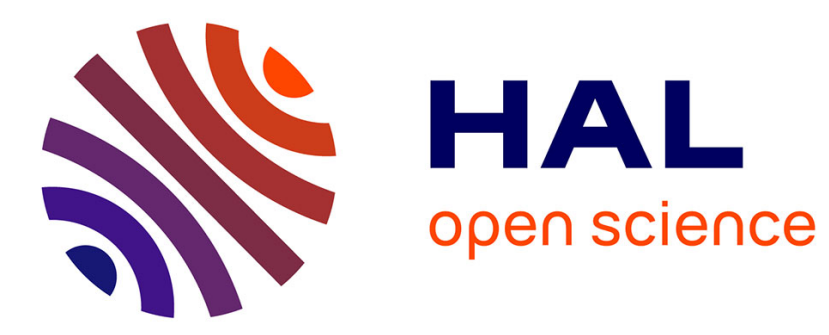

\title{
Interplay between electron affinity and free volume on positronium formation in polyimides
}

\author{
Y. Ito, K.-I. Okamoto, K. Tanaka
}

\section{To cite this version:}

Y. Ito, K.-I. Okamoto, K. Tanaka. Interplay between electron affinity and free volume on positronium formation in polyimides. Journal de Physique IV Proceedings, 1993, 03 (C4), pp.C4-241-C4-247. 10.1051/jp4:1993436 . jpa-00251479

\section{HAL Id: jpa-00251479 https://hal.science/jpa-00251479}

Submitted on 1 Jan 1993

HAL is a multi-disciplinary open access archive for the deposit and dissemination of scientific research documents, whether they are published or not. The documents may come from teaching and research institutions in France or abroad, or from public or private research centers.
L'archive ouverte pluridisciplinaire HAL, est destinée au dépôt et à la diffusion de documents scientifiques de niveau recherche, publiés ou non, émanant des établissements d'enseignement et de recherche français ou étrangers, des laboratoires publics ou privés. 


\title{
Interplay between electron affinity and free volume on positronium formation in polyimides
}

\author{
Y. ITO, K.-I. OKAMOTO* and K. TANAKA* \\ Research Center for Nuclear Science and Technology, The University of Tokyo, Tokai, Ibaraki 319-11, \\ Japan \\ * Faculty of Engineering, Yamaguchi University, Japan
}

\begin{abstract}
Our recent PAL results on a series of polyimides (PI) are summarized. It is shown that PIs are properly grouped according to whether there is long-lived o-Ps or not, and that those that do not produce $0-P s$ have strong electron affinities. Secondly the pore size was changed by exposing PIs to 50 atm $\mathrm{CO}_{2}$ gas. $\mathrm{I}_{3}$ was increased substantially for the PIs that have moderate $\mathrm{I}_{3}$ values. For the PIs that have large o-Ps yield the increase in $I_{3}$ was small, and for those having no o-Ps the o-Ps component did not appear. In a third experiment where the pore structure was changed by introducing vapor molecules, both $\tau_{3}$ and $I_{3}$ were reduced. This contrasts to low density polyethylene for which $\tau_{3}$ and $I_{3}$ were increased. These results are viewed as an aspect of the spur model in which both electron affinity and pore size are affecting Ps formation.
\end{abstract}

\section{Introduction}

The intensity of the longest-lived $e^{+}$component in polymers, the o-Ps component, is affected in various ways, but the mechanisms underlying it have not yet been understood properly. This is related to our lack of knowledge of the mechanism of Ps formation itself, and of how Ps is trapped in open spaces in polymers.

In this report we summarize our recent works on Ps formation in polymers, and show that Ps formation probability is affected both by chemical and physico-chemical factors, and try to explain these different effects. The viewpoint is closely related to the spur model of PS formation.

\section{Positronium Formation in Polyimides}

Kapton film has been known as an excellent material for making positron source because it is highly radiation resistant and there is no long-lived component, i.e. there is no o-Ps formation, in it. But the reason for the absence of 0 -Ps has not been understood. Kapton is a kind of polyimides (PIs) whose principal structure is shown in Fig.1. Various PIs are made by combinations of acid anhydride moieties $\left(R_{1}\right)$ and diamine moieties $\left(R_{2}\right)$, and Kapton is the combination of $R_{1}=1$ and $R_{2}=D(1 D)$. The result of the PAL measurements for a series of PIs are summarized in Table $1^{(1)}$ It is evident that the PIs based on PMDA- and BTDA-moieties have no or little o-Ps component, while those based on BPDA- and 6FDA-moieties show substantial o-Ps formation. Table 1 further suggests that the diamine moieties also affect $0-P_{s}$ formation. For example, those having $D\left(=p p^{\prime}-O D A\right)$ diamine moiety show the smallest $I_{3}$ value of the group having the same anhydride moieties. It is important to note that the absence of 
o-Ps in PMDA- and BMDA-based PIs is not due to lack of free volume holes. This is easily recognized from the data of gas diffusion constants (Table 1) which are not necessarily small for those lacking Ps formation.

Electron affinities of the polyimides are known ${ }^{(2)}$ :

$$
\mathrm{EA}(\mathrm{PMDA})>\mathrm{EA}(\mathrm{BTDA}>\mathrm{EA}(\mathrm{BPDA}) \sim \mathrm{EA}(6 \mathrm{FDA})
$$

Thus it is deduced that Ps yield is intercepted in the PIs whose moieties have large electron affinity. To test the effects of the acid anhydride moieties on Ps formation, monomeric model compounds were synthesized and Ps formation experiments were performed for their

Table 1 O-Ps parameters, gas diffusion constants, and the effect of exposing to high pressure gas for various polyimides

\begin{tabular}{|c|c|c|c|c|c|}
\hline \multirow[t]{2}{*}{ Polyimide } & \multirow{2}{*}{$\begin{array}{r}\tau_{3} \\
(\mathrm{~ns})\end{array}$} & \multirow{2}{*}{$\begin{array}{l}\mathrm{I}_{3} \\
(\%)\end{array}$} & \multirow{2}{*}{$\begin{array}{l}\mathrm{C}_{2} \text { Diffusion } \\
\text { constant } \\
10^{-8} \mathrm{~cm}^{2} \mathrm{~s}\end{array}$} & \multicolumn{2}{|c|}{$\begin{array}{l}\text { After exposing to } \\
50 \text { atm } \mathrm{CO}_{2} \text { gas }\end{array}$} \\
\hline & & & & $\Delta \tau_{3}$ & $\Delta \mathrm{I}_{3}$ \\
\hline \multicolumn{6}{|l|}{ PMDA-based } \\
\hline $1 \mathrm{~A}$ & 1.0 & 0.5 & 4.1 & & \\
\hline $1 \mathrm{D}$ & - & - & 0.8 & & \\
\hline $1 \mathrm{~F}$ & - & - & 0.23 & & \\
\hline 10 & - & - & 5.3 & - & $0 \rightarrow 0$ \\
\hline \multicolumn{6}{|l|}{ BPDA-based } \\
\hline $2 \mathrm{~A}$ & 2.09 & 3 & 1.4 & & \\
\hline $2 \mathrm{~B}$ & 2.67 & 11.7 & 4.6 & & \\
\hline $2 \mathrm{D}$ & 2.52 & 0.5 & 0.18 & & \\
\hline $2 \mathrm{G}$ & 1.79 & 2.3 & 0.33 & $1.44 \rightarrow 1.53$ & $4.6 \rightarrow 7.0$ \\
\hline $2 . J$ & 3.16 & 10 & 16 & . & \\
\hline 20 & 2.34 & 6.3 & 2.4 & & \\
\hline \multicolumn{6}{|l|}{ BTDA-based } \\
\hline $3 \mathrm{~A}$ & - & - & 1.2 & - & $0 \rightarrow \quad 0$ \\
\hline $3 \mathrm{~B}$ & 1.75 & 0.8 & 1.7 & & \\
\hline 3D & - & - & 0.19 & & \\
\hline $3 \mathrm{~J}$ & 1.98 & 1.0 & 4.2 & $1.14 \rightarrow 1.85$ & $1.8 \rightarrow 2.7$ \\
\hline 30 & 1.53 & 0.5 & 1.8 & & \\
\hline \multicolumn{6}{|l|}{ 6FDA-based } \\
\hline $4 B$ & 2.98 & 17.1 & 8.1 & & \\
\hline $4 \mathrm{D}$ & 2.4 & 9.4 & 3.1 & & \\
\hline $4 \mathrm{~F}$ & 2.4 & 7.7 & 1.3 & & \\
\hline $4 \mathrm{G}$ & 2.47 & 12.7 & 2.2 & & \\
\hline 41 & 3.84 & 17.6 & 30.5 & $3.8 \rightarrow 4.9$ & $21 \rightarrow 22$ \\
\hline $4 \mathrm{~J}$ & 3.83 & 15.9 & 54 & $3.5 \rightarrow 4.1$ & $18 \rightarrow 19$ \\
\hline 40. & 2.68 & 16.5 & 5.7 & & \\
\hline $4 \mathrm{~S}$ & 3.15 & 14.3 & 6.5 & & \\
\hline $4 \mathrm{~T}$ & 2.72 & 10.9 & 2.6 & & \\
\hline $4 U$ & 2.57 & 7.9 & 0.81 & $2.4 \rightarrow 2.86$ & $8 \rightarrow 13.4$ \\
\hline $4 \mathrm{~V}$ & 2.8 & 11.3 & 6.2 & & \\
\hline
\end{tabular}

(-) meons that there was no long-lived component in the PAL spectrum. 


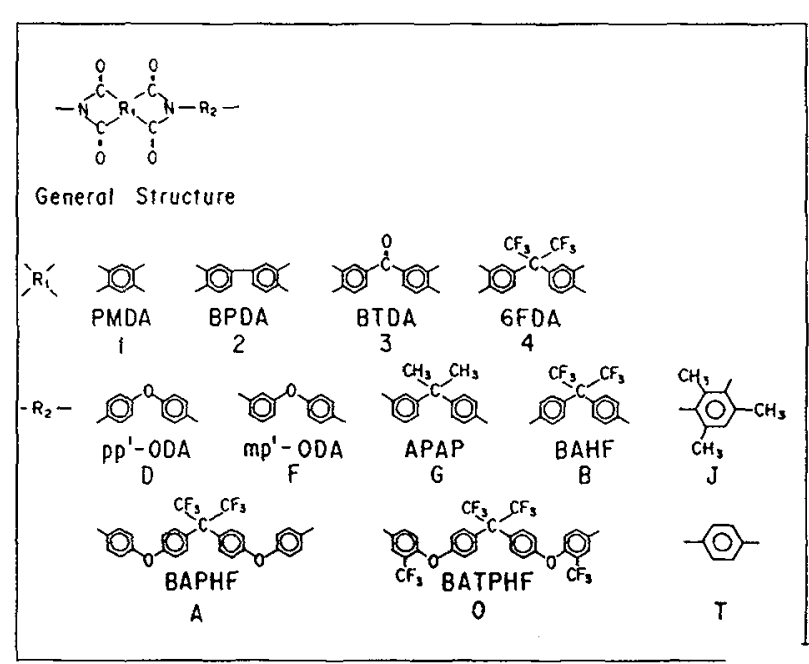

Fig. 1

The structure of polyimides.

Various Pls are synthesized by combinations of the acid anhydride moieties ( $R$ ) and the diamine moieties $\left(R_{2}\right)$, and are numbered as 1D for PMDA/pp'ODA (commercial name : Kapton). PMDA : pyromellitic dianhydride BTDA : $3,3^{\prime}, 4,4^{\prime}$-benzophenonetetracarboxylic dianhydride

BPDA : 3, 3' 4, 4'-biphenyl tetracarboxylic dianhydride

6FDA: 2,2-bis (3,4-dicarboxypheny 1) hexafluor opropane dianhydride

benzene solutions. Prior to the measurements the solutions were bubbled with benzene-saturated nitrogen gas to eliminate oxygen. The results are shown in Fig.2. Because the solubility of the monomeric imides is low, the concentration range is below c.a. $80 \mathrm{mM}$. Evidently PMDA-BA is the strongest, and BTDA-BA is the second strongest, inhibitor and quencher of Ps. On the other hand, BPDA-BA and 6PDA-BA has no effect both on 0-Ps intensity and lifetime. This result also correlates well with the order of the electron affinity shown in Eq.1. An important conclusion is that PMDAand BTDA- can both inhibit $P_{S}$ formation and quench o-Ps lifetimes. Coming back to Table 1 with this in mind, we notice that the PIs having small $I_{3}$ values also show short $0-P S$ lifetimes. Undoubtedly Ps formation and reactions in the PIs are controlled by the same mechanism as in the model solutions. It is important to recognize that $0-$ Ps lifetime can be affected not only by the volume factors but also by chemical reactions. It will be sometimes dangerous to try to correlate the o-Ps lifetimes with the size of free volume holes without knowing whether the factors of chemical reactions are not prevailing on the o-Ps lifetimes or not.

Fig.2

Positronium formation experiments for benzene solutions of model imide compounds (aromatic imides). (No source correction.) It is shown that, while BPDA-BA and 6FDA-BA have no effect, PMDA-BA $\quad\left(k q=13.2 \quad \mathrm{M}^{-1} \mathrm{~s}^{-1}\right)$ and BTDA-BA $\left(k q=5.2 \mathrm{M}^{-1} \mathrm{~s}^{-1}\right)$ both inhibit Ps formation and quench o-Ps lifetimes. $K q$ in the parentheses are the quenching rate constants. 


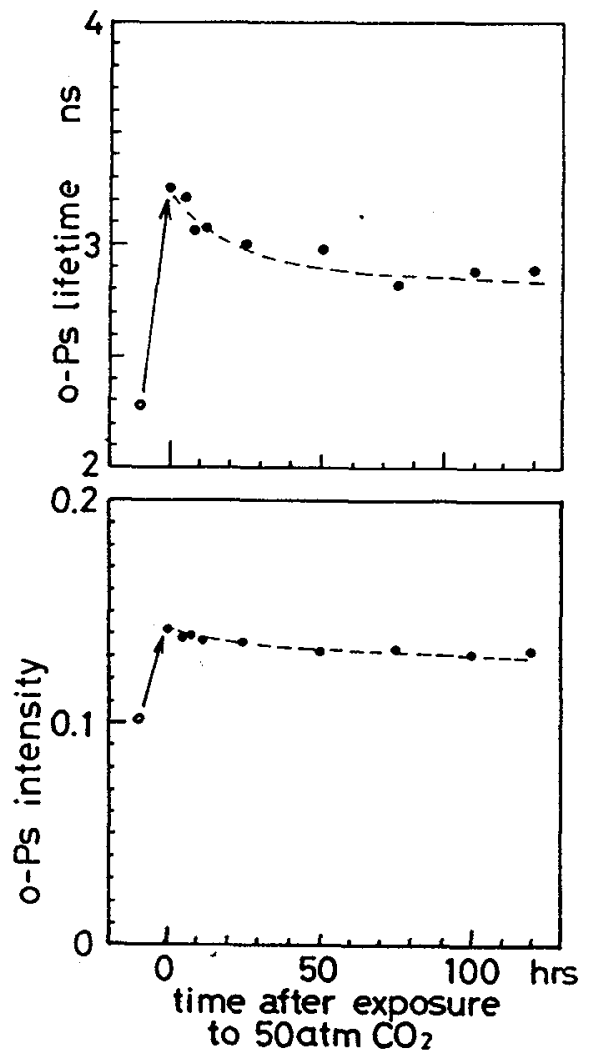

Fig. 3 to $50 \mathrm{~atm} \mathrm{CO}_{2}$ gas. The arrows show the increase of $0-P s$ lifetime and intensity due to the exposure. After that both the lifetime and the intensity gradually relax back, but not completely to their initial values.
Effects of exposing polyimide (PI-4U)

\section{Effect of Exposing to High Pres- sure Gas}

Some of the PIs were exposed to 50 atm of $\mathrm{CO}_{2}$ gas to expand the free volume holes, and PAL were measured under vacuum before and after the treatments. The results are also shown in Table 1. For the PIs for which there is no long-lived o-Ps component $(10,3 \mathrm{~A})$, there was no change in the PAL spectrum. For those having large $0-P s$ intensity $(4 I, 4 J) I_{3}$ increased only slightly. For those having small $I_{3}$ value $(2 G, 4 U)$ the increase in $I_{3}$ was substantial. By this treatment the lifetime of $0-\mathrm{Ps}_{\mathrm{s}}$ if it exists, also increased by 20-30\%. An example of the change of PAL data is shown in Fig. 3.

After exposed to $\mathrm{CO}_{2}$ gas and then evacuated, the o-Ps parameters gradually changed to an equilibrium state which is apparently different from that before the gas exposure. This interesting fact will be discussed elsewhere. ${ }^{(5)}$

Low density polyethylene (LDPE) was also exposed to high pressure $\mathrm{CO}_{2}$ gas, but there was no observable change before and after the gas treatment. Since LDPE is in a rubbery state, i.e. at thermal equilibrium at room temperature, the change of the structure caused by the penetrating gas may quickly resume to initial structure after evacuating the gas.

\section{Effects of gas sorption in poly- mers}

Another way to change the state of free volume holes is to get vapor molecules sorbed in it. This was done for a kind of polyimide $(\mathrm{PI}-4 \mathrm{~J})$ and low density polyethylene (LDPE) $)^{(3)}$ and polypropylene and polytetrafluoroethylene $^{(4)}$. An important result (shown in Fig.4) is that both $I_{3}$ and $\tau_{3}$ are decreased when PI-4J sorbs vapors, while they are increased when LDPE sorbs them, irrespective of the kind of the vapor used (n-hexane, cyclohexane, benzene, acrylic acid, etc.). In the case of PI-4J, which is glassy at room temperature, $\mathrm{I}_{3}$ and $\tau_{3}$ may decrease, because the vapor molecules are sorbed by depositing in free volume holes (Langmuir type sorption) and makes the number and the size of space available for Ps smaller. In the case of LDPE, which is rubbery at room temperature, the sorbed molecules "dissolve" into the polymer chains (Henry type sorption), and results in so-called plasticization. The polymer chains acquire more mobilities and, as envisaged from the in 

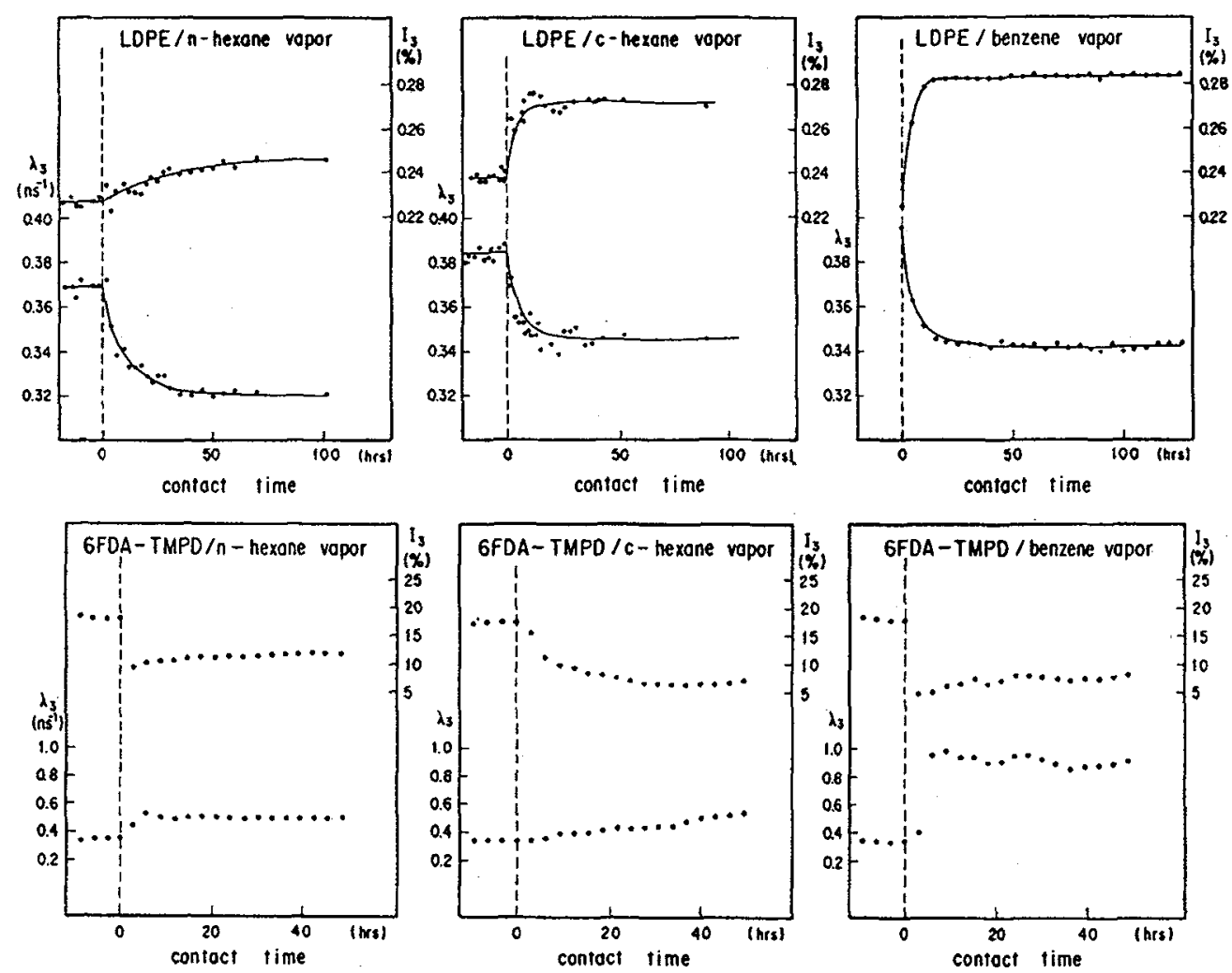

Fig.4 The changes of o-PS parameters in LDPE (upper row) and 6FDA-TMPD (or $4 \mathrm{~J}-\mathrm{PI}$ according to the symbol of Fig.1, lower row) as a function of the contact time with the vapor of nonpolar molecules, n-hexane, cyclohexane and benzene. Note that the changes are opposite for LDPE and $4 \mathrm{~J}-\mathrm{PI}$ irrespective of the kind of the vapor molecules.

creased specific volume, the equilibrium free volume structure shifts to larger sizes and broader distribution. In this case there are as many or more space for Ps as before the gas sorption. This is the reason for the increased $I_{3}$ and $\tau_{3}$ in $\mathrm{LDPE}$.

\section{Intexplay between electron affinity and hole size}

Our data show that both electron affinity and hole characteristics (the number and the size) are affecting $0-P s$ intensity. The role of the electron affinity should be closely related to the aspect of the "spur model". We will introduce an idea in which the holes are involved in the recombination process of $\mathrm{e}_{\mathrm{m}}^{+}$and $\mathrm{e}_{\mathrm{m}}^{-}$.

$$
\mathrm{e}_{\mathrm{m}}^{+}+\mathrm{e}_{\mathrm{m}}^{-} \rightarrow \mathrm{Ps}_{\text {hole }}
$$

Its energetics may be described as;

$$
-E\left(e_{m}^{+}\right)-P_{\text {sol }}\left(e_{m}^{+}\right)-E\left(e_{m}^{-}\right)-P_{\text {sol }}\left(e_{m}^{-}\right)+E\left(P_{s_{h o l e}}\right)<6.8 \mathrm{eV}
$$


where $E\left(e_{m}^{+}\right)$and $E\left(e_{m}^{-}\right)$are the energies of Ps precursors in the matrix and $E\left(P_{s_{h o l e}}\right)$ is the energy of Ps in the hole, all measured from the vacuum level. $P_{\text {sol }}$ is the solvation energy of et and $e-$ and, according to the Born expression is given by, $-e^{2} / 2 a(1-1 / \varepsilon)$, where $a$ is the average radius of the charged state and $\varepsilon$ is the static dielectric constant of the medium. Thus Ps will not be formed when $\mathrm{e}_{\mathrm{m}}^{+}$and/or $\mathrm{e}_{\mathrm{m}}^{-}$are deeply trapped, or when the hole size is too small and hence $\mathrm{E}\left(\mathrm{PS}_{\mathrm{s}_{\text {hole }}}\right)$ is large. Since electron affinity is small or none in $\mathrm{LDPE}$, Ps formation is favorable in it. Indeed $\mathrm{I}_{3}$ in LDPE is larger than that in PIs (see Fig.4 and Table 1). All the PIs studied have electron affinities, but those having small affinities may be satisfying Eq.3 and can form Ps. From this viewpoint it would be principally possible to find an energetic criterion between PMDA- and BTDA-based PIs (for which Eq.3 does not hold) and BPDA- and 6FDA-based PIs (for which Eq.3 holds), or in other words between EA for BPDA $(1.38 \mathrm{eV})$ and EA for BTDA $(1.55 \mathrm{eV})$. Although possible differences of the positron affinities must further be taken into account, we make a crude assumption that they are approximately the same for all the polyimides. We further estimate the pore sizes from the larger $\tau_{3}$ values in Table 1 ( $2.5 \sim 3.5 \mathrm{~ns} \rightarrow \mathrm{R}=.34 \sim .39 \mathrm{~nm}$ ), because, as has been pointed out, small $\tau_{3}$ values probably come from chemical reactions. The zero point energy of $P s$ in the pores is then calculated $\left(E_{0}=0.188 \mathrm{eV} / R^{2}\right.$ for a potential well with infinite height $)$, and possible range for the positron energy in PIs is derived as

$$
\mathrm{E}\left(\mathrm{e}_{\mathrm{m}}^{+}\right)+\mathrm{P}_{\text {sol }}\left(\mathrm{e}_{\mathrm{m}}^{+}\right)+\mathrm{P}_{\text {sol }}\left(\mathrm{e}_{\mathrm{m}}^{-}\right)=-3.6 \sim-4.2 \mathrm{eV} \text {. }
$$

Since the solvation energies would be $-1 \sim-2 \mathrm{eV}$ for both $\mathrm{e}^{+}$and $\mathrm{e}^{-}$, the positron energy in the medium can be close to zero, i.e. positrons are not trapped strongly.

It is presupposed in Eq.2 that Ps formation takes place at the hole sites. Both $\mathrm{e}_{\mathrm{m}}^{+}$and $\mathrm{e}^{-}$would be diffusing by random walk or by hopping from a trapping site to another. It is not always that they make Ps on encountering each other because, if there is no hole nearby or if the holes are small, the energy condition (Eq.3) is not favorable. This is especially so for PIs for which the energy condition is already unfavorable due to large electron affinity. When there are favorable free volume holes, Ps formation probability will be determined as a result of competition of positron annihilation rate and $\mathrm{e}^{+} / \mathrm{e}^{-}$encounter rate. The mobilities of $\mathrm{e}^{+}$ and $\mathrm{e}^{-}$and the number of available free volume sites should play an important role in the latter, and in this way the number of free volume sites may be correlated to $I_{3}$.

An important consequence of the interplay between electron and positron affinities and hole size is that there is a cut-off level in the size of the free volume holes. Free volume holes whose sizes are above the cut-off level should not be available as Ps formation sites. The cut-off level is determined from the energy condition 3 and hence it depends on the values of the affinities.

If the hole sizes are made larger as was done in the high pressure gas exposure experiments, the energy condition shifts to a more favorable side, i.e. the fraction above the cutoff level increases. This is what is observed for the PIs having moderate $\mathrm{I}_{3}$ values $(2 \mathrm{G}, 4 \mathrm{U}$ in Table 1). For the PIs having large $I_{3}$ values (4I, 4J), Eq.3 should be already satisfied for most ensemble of $\mathrm{e}^{+}{ }_{\mathrm{m}}+\mathrm{e}_{\mathrm{m}}^{-}$pairs and an enlargement of the pore sizes is not much useful to further increase the $\mathrm{I}_{3}$ value. For the PIs that have no $0-\mathrm{Ps}$, the energy is out of condition even if the hole sizes are made larger. 


\section{Conclusion and a short comment on the aspects of the models of Ps formation}

Ps formation in PIs is shown to be influenced both by the chemical factors (the electron affinity) and the volume factors, and a view that incorporates both effects are presented. Even this view will reflect only a part of complicated spur processes involved. An important conclusion from this view is that $l_{3}$ by no means a direct measure of the "number" of free volumes. Only in polymers having like chemical compositions with small affinities the correlation between $I_{3}$ and the number of free volume sites would be substantiated. It further follows from the previous view that an increase (decrease) in $I_{3}$ does not necessarily imply an increased (decreased) number of free volume sites

As has frequently been pointed out by us and others, at least a part of Ps formation is better understood from the viewpoint of the spur model. This paper also deals with such aspect. But other fraction of Ps, which are unscavengeable and independent of small perturbations, appears to have the aspect of the Ore model. It is not difficult to think about a mechanism which can combine both aspects of Ps formation, and an idea for such direction will be published by us in due course. For the present purpose. we emphasize that we have used the expression "the aspect " of the spur model or "the aspect" of the Ore model. Any arguments that is made to fight against one side of the models from the other, and vice versa, would be fruitless because they are mostly discussing from the different "aspects".

\section{Acknowledgement}

Stimulating discussion with late Dr. Ole E. Mogensen during his one-and-half-a-year stay in Japan, and that with Dr. Y. Kobayashi are highly appreciated. Ole viewed our data herein with a particular enthusiasm and discussed. We dedicate this paper to 0le.

\footnotetext{
/1/ Okamoto,K, Tanaka,K, Katsube,M, Sueoka,O, and Ito,Y, Radiat. Phys. Chem.41(1993) 49

/2/ Svethichnyi,V.M, Dokl. Akad. Nauk SSSR , 237(1977)612

/3/ Ito,Y, Sanchez,V, Lopez,R, Fucugauchi,L.A, Tanaka,K, and Okamoto,K; Bull. Chem. Soc. Jpn, 66(993)727

/4/ Sanchez,V, Lopez, R, and Ito, Y; to be published

/5/ Okamoto, Tanaka, Tanihara, Ito; to be published
} 